\title{
Ergonomics Observation: Harvesting Tasks at Oil Palm Plantation
}

\author{
Yee Guan NG ${ }^{1}$, Mohd Tamrin Shamsul Bahri ${ }^{1}$, Md Yusoff Irwan SyaH ${ }^{2}$, Ippei Mori ${ }^{3}$ and \\ Zailina HASHIM ${ }^{1}$ \\ ${ }^{1}$ Department of Environmental and Occupational Health, Faculty of Medicine and Health Sciences, Universiti Putra \\ Malaysia, Malaysia ${ }^{2}$ Department of Resources Management and Consumer Studies, Faculty of Human Ecology, \\ Universiti Putra Malaysia, Malaysia and ${ }^{3}$ Department of Public Health and Occupational Medicine, Mie University \\ Graduate School of Medicine, Japan
}

\begin{abstract}
Ergonomics Observation: Harvesting Tasks at Oil Palm Plantation: Yee Guan NG, et al. Department of Environmental and Occupational Health, Faculty of Medicine and Health Sciences, Universiti Putra Malaysia, Malaysia-Objectives: Production agriculture is commonly associated with high prevalence of ergonomic injuries, particularly during intensive manual labor and during harvesting. This paper intends to briefly describe an overview of oil palm plantation management highlighting the ergonomics problem each of the breakdown task analysis. Methods: Although cross-sectional field visits were conducted in the current study, insight into past and present occupational safety and health concerns particularly regarding the ergonomics of oil palm plantations was further exploited. Besides discussion, video recordings were extensively used for ergonomics analysis. Results: The unique commodity of oil palm plantations presents significantly different ergonomics risk factors for fresh fruit bunch (FFB) cutters during different stages of harvesting. Although the ergonomics risk factors remain the same for FFB collectors, the intensity of manual lifting increases significantly with the age of the oil palm trees-weight of FFB. Conclusions: There is urgent need to establish surveillance in order to determine the current prevalence of ergonomic injuries. Thereafter, ergonomics interventions that are holistic and comprehensive should be conducted and evaluated for their efficacy using approaches that are integrated, participatory and cost-effective.

(J Occup Health 2013; 55: 405-414)
\end{abstract}

Key words: Ergonomics, Harvesters, Musculoskeletal

Received Jan 17, 2013; Accepted Jun 2, 2013

Published online in J-STAGE Jul 26, 2013

Correspondence to: Y.G. Ng, Department of Environmental and Occupational Health, Faculty of Medicine and Health Sciences, Universiti Putra Malaysia, 43300 UPM Serdang, Selangor Darul Ehsan, Malaysia (e-mail: shah86zam@medic.upm.edu.my) disorders, Oil palm, Sustainability

As the global population continues to expand, the world's food and energy consumption has increases accordingly. Changes in eating habits and increases in global food demand require that the food productions to be intensified to keep up with the already shortage in global food supply and cultivable land ${ }^{1-3)}$. Additionally, the world's fast depleting fossil fuel energy reserves have also led the search for a viable substitute source of energy to food as biofuel ${ }^{4)}$.

Eventually, palm oil emerged as the most productive oil crop with a value chain spanning from the upstream plantation to downstream industrial processing activities ${ }^{5-7)}$. Featured as the most produced and traded vegetable oil, the seeds of the oil palm have the greatest average oil yield potential per hectare per year as compared with other oil seeds ${ }^{8}$. Additionally, it is a highly productive crop with a high output-toinput biomass energy ratio of 9:1 as compared with the $3: 1$ ratio of most other plants' biomass ${ }^{9)}$.

While it has been suggested that palm oil may indeed be the solution to increasing food and energy consumption and demand ${ }^{7,8,10,11)}$, the industry has also been associated with social development in uplifting of poverty through employment in various streams of the value chain as well as infrastructure development ${ }^{1,12-14)}$.

In recent advancements, the sustainability of the palm oil industry has gained much attention from various international stakeholders, both governmental and non-governmental organizations. In particularly, the sustainable plantation practices addressing the 3Ps-profit (economics), people (social) and planet (environment) - have been highlighted (Fig. 1) since the rapid expansion of the oil palm industry ${ }^{8,10,13,15,16)}$. Malaysia, which is at the forefront of oil palm 


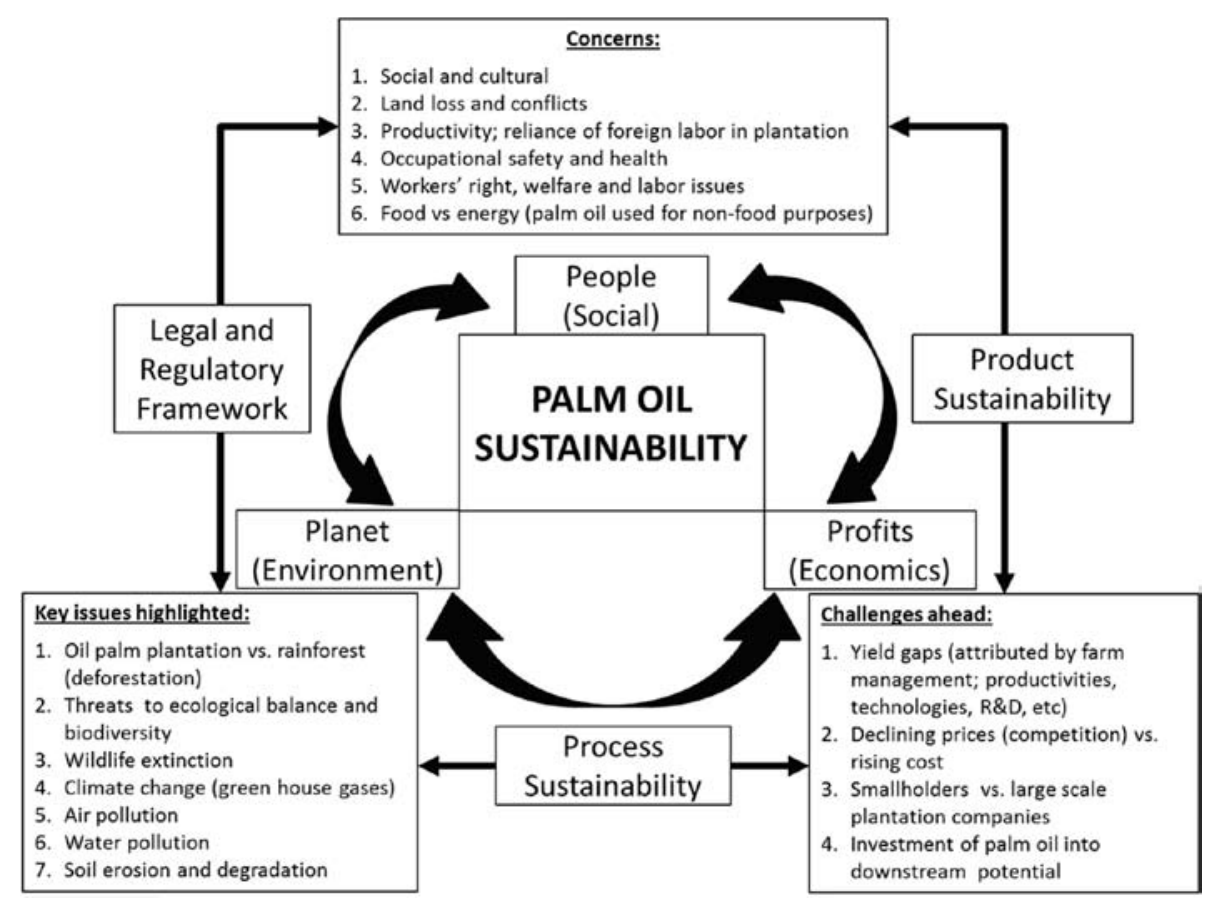

Fig. 1. Conceptual framework of palm oil Industry sustainability.

industry development, has recently reported serious fallback of labor requirements due to heavy reliance on foreign labor ${ }^{17)}$. A study by Abdullah et al. (2011) revealed the statistics of workforce participation according to job categories in the upstream plantation activities, which naturally skewed towards harvesting tasks, as in this case, harvesting and collection of fresh fruit bunches (FFBs) as in many other agricultural practices.

The findings in various studies ${ }^{19,20)}$ have revealed that labor-intensive agricultural practices have been associated with high prevalence of musculoskeletal disorder (MSD). In a review article, Kirkhorn, EarleRichardson, and Banks (2010) highlighted the association of ergonomics risk factors and MSDs with the agricultural commodities. It can be observed that MSDs were prevalent among traditional manual harvesting practices.

Unfortunately, despite the intensive manual handling and labor activities involved in harvesting at an oil palm plantation (OPP), the agricultural ergonomics at the OPP have yet to be recognized, with only few articles related to ergonomics in OPP work activities published in local publications. Thus, this article intends to describe briefly an overview of work activities at a typical OPP and subsequently focus on the potential risk factors towards development of ergonomic problems during harvesting activities.

\section{Methods}

The present study involves ten OPPs in Malaysia that were centrally monitored by a regional office but managed by the respective management teams of the separate OPPs. A chain of command system was used in their organization in which each OPP management team reported to and executed the results of planning by the regional office based on policy cascaded down from their headquarters.

The criteria chosen for the site visits in this study were as follow (1) the site had young palm trees between 3-6 years old, (2) it was in its early harvesting years (1st to 3rd harvesting year), and (3) the site was using a chisel, metal pole or hook and a wheelbarrow for harvesting tasks. The majority of the workers including harvesters were foreign laborers. Prior to a site visit, approval was obtained from the regional office, which requested plantation anonymity to prevent identification of the organization.

During each site visit, a discussion was held between the research team and manager or representative of the OPP. This was in order to understand better the management system and occupational safety and health practices at the respective OPP. Subsequently, plantation supervisors were in charge of providing us field information and filling in the gaps, in addition to guiding us in locating harvesters for video recording.

Video recordings of harvesting tasks were subse- 
quently viewed by two trained ergonomists and a professional ergonomist to analyze the associated ergonomics risk factors, which were primarily related to postural aspects. The data and information from informal interviews and discussions were also used to reinforce our findings, which were visually observable or unavailable during data collection (such as land clearing).

\section{The oil palm industry value chain}

As summarized in Fig. 2, the oil palm industry encompasses 4 major activities, the upstream oil palm plantation, midstream processing, downstream application and research and development (R\&D). The upstream agricultural activities produce palm fruits that are rich sources of oil, while the midstream processing involves not only extraction of crude and kernel oil but also biomass and animal feeds from the oil palm fruits and tree wastes.

Thereafter, these intermediate products are then delivered to various industries for diversified downstream applications. In a special category by itself, R\&D, especially of biotechnology, has a major role to play in deriving various applications not only for downstream uses but also for the benefit of the upstream oil palm plantation benefits such as genetic manipulation of seeds, soil, fertilizers and plantation management, mechanization, etc.

\section{The cycle of oil palm plantation}

Usually, germination of oil palm seeds and management of seedlings a nursery are carried out prior to, or concurrently with establishment of a plantation. After the land has been cleared off, soil work such as terracing, conditioning, irrigation, weeding and cultivation of cover crops are commenced. Once the land is prepared, the ready young palm seedlings are transplanted to the plantation.

Subsequently, the plantation is managed for 3-4 years, during which weeding, pesticides and herbicides spraying, fertilizers application and pruning are carried out until the oil palm fruits, fresh fruit bunches (FFBs) are ready for harvesting. In a typical oil palm plantation, harvesting tasks are performed in a team of 2 workers, an FFB cutter and FFB collector, and as frequent as 3 cycle/visits per month are carried out for each tree.

Harvested fruits are subsequently sent to an oil palm mill for oil extraction by truck, which is loaded separately by another category of workers known as loaders. Typically, an oil palm plantation has a lifespan of 25-30 years of production before FFB production finally declines to an unprofitable output level. Thereafter, the cycle of land clearing and preparation is repeated for replanting processes.

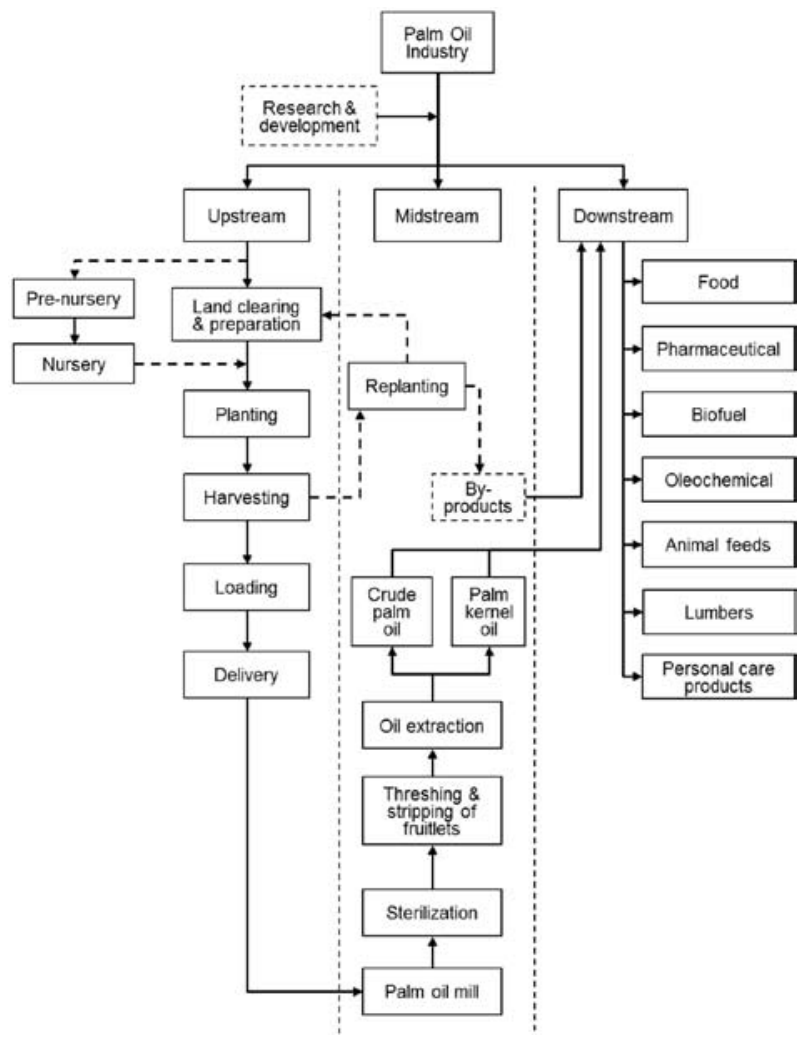

Fig. 2. Process flow chart of upstream oil palm plantation and value chain of downstream application of the oil palm industry.

\section{Results}

\section{Harvesting activities-FFB cutter}

The harvesting stages can be divided according to the tools used at the respective stage. In the early stage of harvesting, typically during the first 3 years of manual harvesting (young palm trees typically at 3-4 years old to 6-7 years old), a chisel attached to a hollow metal pole (usually galvanized iron-GI) is used to harvest the FFB. The estimated weight of the chisel made using GI is from $2 \mathrm{~kg}$ to $3 \mathrm{~kg}$ depending on the length of the pole which is based on individual preferences.

Two main tasks are performed using a chisel or sickle; cutting the ripe oil palm fruit and pruning task (Fig. 3). The FFBs are detached from the oil palm tree by cutting the exposed bunch stalk, while pruning is performed by cutting the oil palm frond at the base of the trunk. However, use of a chisel is limited by the height of the FFB typically, it is used at a height within 0.5 meters to 3 meters above ground (Fig. 3a, $3 b)$.

During the early stage of harvesting, when a ripe FFB is identified, an FFB cutter approaches the tree bearing the ripe oil palm fruit. While looking for a 

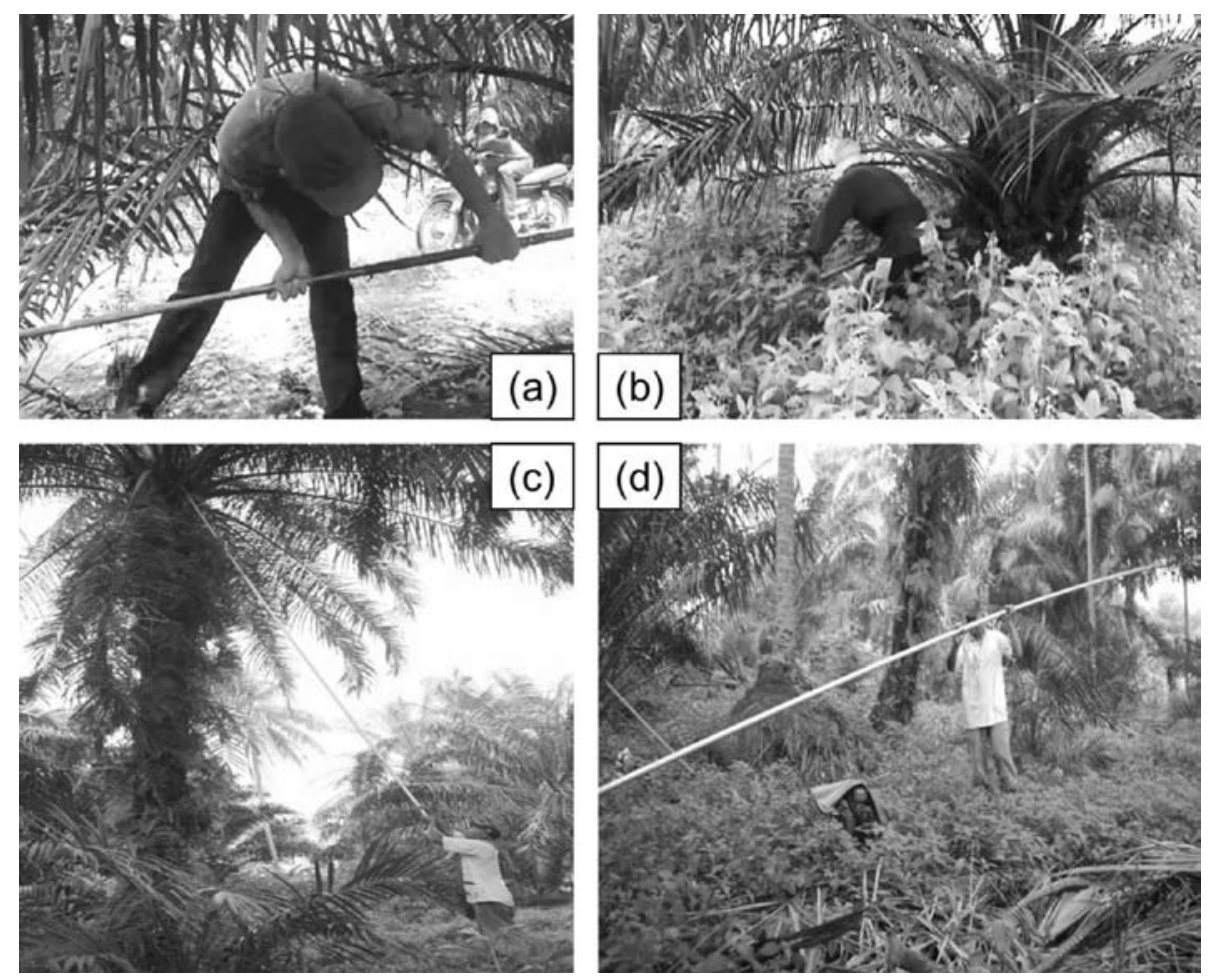

Fig. 3. FFB cutter; (a) stooping while performing harvesting task, (b) canopy arrangement of oil palm trees affecting posture, (c) performing harvesting task with head tilted upward and both hand above shoulder, (d) balancing and manoeuvring long sickle to erect pole for harvesting task.

strategic location based on the stalk of the fruit, they establish a firm foothold and move their body into a suitable position by aligning the body in horizontal direction with the stalk of the ripe FFB. Then, cuts are made by repeatedly exerting push and pull forces.

As the oil palm trees grow, the height at which the FFBs are located increases correspondingly. At 6-7 years old, the fruits on the palm tree are approximately 3 meters above the ground. At this time, the FFB cutter uses either a chisel or sickle, switching among the two depending on whichever is more convenient for performing the job tasks. For trees beyond 7 years old, the FFB cutter will only use a sickle. At the height at this age, they naturally tilt their heads upward in order to locate ripe fruits.

Oil palm trees at 25 years old are capable of growing up to 20 metres. As the trees grow continuously, the height of the fruits ascends correspondingly. The FFB cutter is thus required to continuously tilt their head upward as they cut the stalks of FFBs on the trees including during pruning (Fig. 3c). With the increase in tree height, the sickle's length needs to be extended in order to reach the stalks of the fruits and fronds of the trees. Hence, the length will be extended by manually attaching more poles by tying them together (Fig. 3d). In consideration of the poles height which could extend up to 20 meters high above the ground level, stability and strength for manoeuvring the sickle during cutting and during transfer from tree to tree are necessary.

\section{Harvesting activities - FFB collector}

On the other hand, an FFB collector will pick up the detached FFB on the ground using either a hook or metal pole to pierce and load them onto a wheelbarrow (Fig. 4). Thereafter, FFB collector will collect the loose fruits on the ground by sweeping them (Fig. 5a, 5b). However, if the wheelbarrow is left further from the fruit being collected, the FFB will have to be carried over a greater distance.

When the wheelbarrow is full, the FFB collector will push it to the roadside along the main truck route and unload it (Fig. 5c, 5d). Subsequently, loaders, who are also frequently the drivers of the trucks will stop at each collection point along the main route to load all the fruits including loose fruits to be sent to the oil palm mill.

\section{Ergonomic problems during harvesting-FFB cutter}

Based on the described task breakdown analysis, oil palm harvesters are exposed to multiple ergonomics risk factors of developing MSDs. For FFB cutters, 

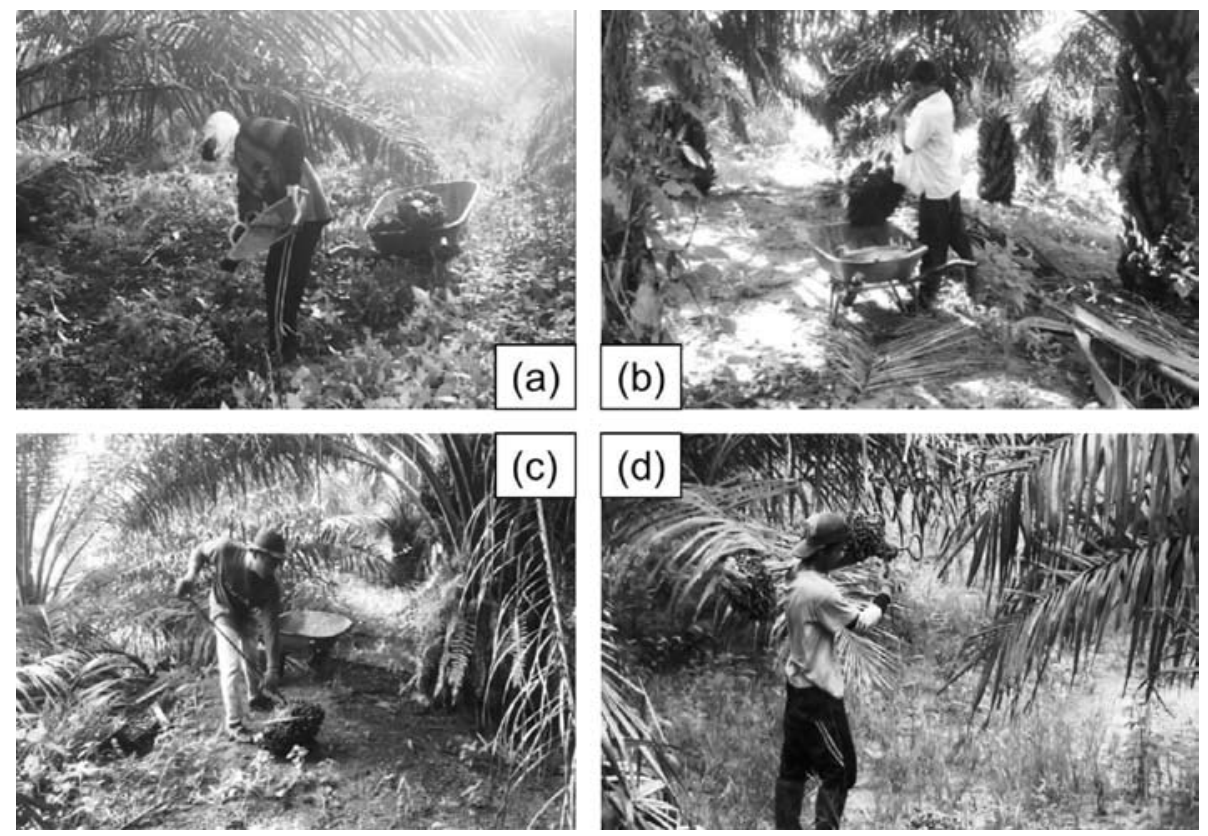

Fig. 4. FFB collector; (a) lifting FFB using hook from the ground with a single hand to load into wheelbarrow, (b) lifting FFB using hook with both hand to load onto wheelbarrow, (c) lifting FFB using metal pole onto wheelbarrow, (d) lifting and carrying FFBs over a distance to where wheelbarrow are left.
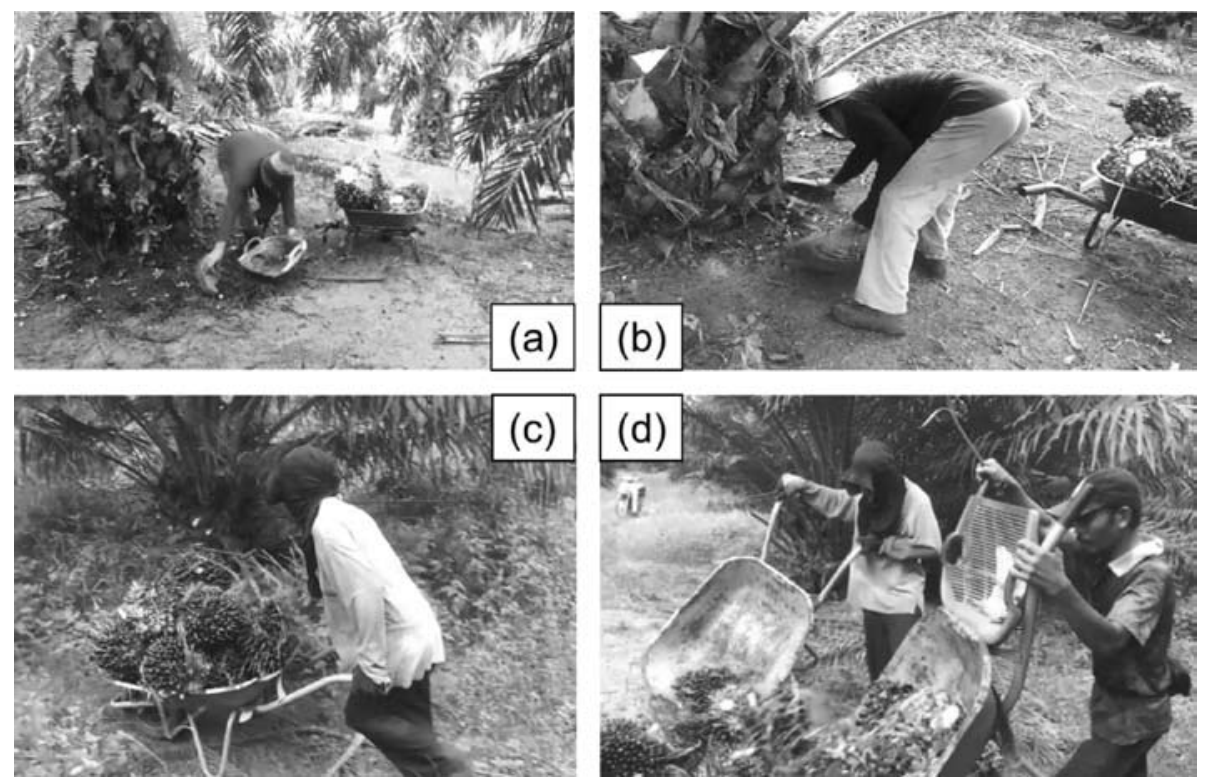

Fig. 5. FFB collector; (a) and (b) collecting loose fruit scattered on ground by sweeping in stooping posture, (c) pushing fully loaded wheelbarrow with back posture bent forward, (d) unloading wheelbarrow at truck collection route point.

stooping appears to be most significant posture at the early stages of harvesting (Fig. 3). Moreover, during cutting, the trunk and neck were also observed to be slightly rotated and being flexed forward while the hand was forcefully pushing-pulling/swinging the chisel outside or across the body midline.
The degree of the trunk flexion varies according to several factors, harvester's height ${ }^{23)}$, the height of the FFBs on the palm trees and the work environment. In terms of work environment, the fronds of young oil palm trees branch out in a canopy arrangement (Fig. 3). This indirectly promotes further bending as harvesters 
avoid the pointy and sharp leaves of the palms which may cause cut-type injuries to the skin.

Contrary to the visual perception (in Fig. 3), the author (who had no prior experience) found in an attempt to cut an FFB had found that the energy required is intensive. Furthermore, in order to perform a clean cut of the FFB stalk at the base of the oil palm trunk, a certain precision and balancing of the chisel, which are gained by experience, are necessary in addition to brute strength.

When the oil palm trees gain a certain height, which corresponds to their age, FFB cutter need to tilt their heads upward. Consistent with the task requirement, FFB cutters must first identify ripe FFBs before extracting them from the trees. Subsequently, FFB cutters will balance the sickle and lift it to the appropriate height to cut the FFB stalk with their arm extended frontward and above their head (Fig. 3c). In consideration of both job requirements, FFB cutters will need to tilt their heads upward for the entire day the work is being carried out.

Ergonomic problems during harvesting-FFB collector Similarly, collection of FFBs is also a laborintensive work task. In the early harvests, an FFB can weigh an average of around $5 \mathrm{~kg}$. However, as the trees become older, the size and weights of FFBs increase, with FFB of the oil palm tree at $>15$ years old weighing as much as $50 \mathrm{~kg}^{24}$. Regardless of the size and weight, the repeated forceful manual collections of the FFBs are also usually carried out alone.

As can be identified from Fig. 4, the tasks using either a hook or metal pole for lifting and loading FFBs from the ground generally require the FFB collector to bend forward and with a twisting posture during lifting (Fig. 4a, 4c). The posture becomes more severe when lifting heavier FFBs and sustaining the posture during loading of FFBs onto wheelbarrow to minimize any impact that could potentially detach or scatter loose fruit as well as damage the quality of the fruit.

On the other hand, collection of scattered loose fruits was carried out manually by sweeping over an area. This task indirectly promotes a stooping posture in addition to overreaching as the FFB collector extends their hands and arms to sweeps fruits that are scattered beyond the area within arm's length reach area. Although this action is performed in a short period of time, it is however repeated daily with high frequency.

Additionally, in our observations, in order to overcome labor shortages and minimize the costs of operation, harvesters are usually assigned to cover a larger harvesting area hence potentially extending the period of harvesting round (exceeding 10 days/ round/month). Thus, motivated by the increase in profit sharing wages, which are calculated in terms of group productivity, harvesters were observed working at a high pace despite experiencing fatigue in order to finish their harvesting rounds (to keep it within 10 days/round/month).

\section{Discussion}

Based on the work tasks of oil palm harvesters described, both FFB cutters and collectors are exposed to a considerable combination of adverse ergonomics work conditions that depend upon the age of the oil palm trees. The changing environment of the plantation environment is one unique feature of the OPP, as it influences the workplace ergonomics risk factors and exposures depending on the physical growth of the trees in different harvesting stages.

In the early stage of harvesting, the FFB cutter suffers especially from postural stress due to awkward postures and stooping in addition to forceful exertion and a rapid work pace. The body areas potentially affected during this harvesting stage are the lower back, upper back, hands and arms due to the nature of the job or task requirement, the worker harvests the oil palm fruit typically at knee level in the early stage.

However, at a later stage of harvesting, as the FFB cutter will subsequently assume a standing posture, the upper back becomes the most affected body part. Corresponding to tree height, extraction of FFBs from a tree is carried out with a combination of adverse ergonomic postures in which the neck is tilted upward while the hands and arms extended and the shoulder are flexed beyond the shoulder height for a prolonged period of time.

On the other hand, the manual handling tasks of lifting carried out by FFB collectors also possess a major ergonomic hazard. Manual handling of FFBs, which requires greater physical effort, becomes more significant as the oil palm trees mature, resulting in an increase of FFB weight. In this case, the entire body of the FFB collector may be affected in consideration of the repeated forceful effort required during loading of FFBs onto a wheelbarrow.

In addition, FFB collectors also experience postural stress, particularly in the lower back and shoulders, during stooping and overreaching to collect loose fruits. When the wheelbarrow is fully loaded, the FFB collector will need to exert upper and lower body strength in balance in order to maintain stability to prevent tripping and spilling. At a poorly maintained plantation, greater exertion may be required to push the wheelbarrow along the uneven landscape or through the overgrowth of surface vegetation.

Prior to 20th century, MSDs and ergonomics in 
Table 1. Summary of studies associating different ergonomics risk factors to different body parts MSD

\begin{tabular}{|c|c|c|}
\hline $\begin{array}{l}\text { Commonly affected body } \\
\text { part/region } \\
\text { (potential MSDs) }\end{array}$ & $\begin{array}{l}\text { Task movement / Ergonomic } \\
\text { risk factors }\end{array}$ & References \\
\hline Neck disorders & $\begin{array}{l}\text { Repetitive work } \\
\text { Forceful work } \\
\text { Static contraction } \\
\text { Extreme working postures }\end{array}$ & $\begin{array}{l}\text { NIOSH (1997); Walker-Bone \& Palmer } \\
\text { (2002); Rosecrance et al. (2006); Davis } \\
\text { (2007); Osborne } \text { et al. (2010); Fathallah } \\
\text { (2010) }\end{array}$ \\
\hline Shoulder disorders & $\begin{array}{l}\text { Repeated or sustained exertions } \\
\text { Forceful exertion } \\
\text { Awkward or sustained posture } \\
\text { (shoulder flexion or abduction }\end{array}$ & $\begin{array}{l}\text { NIOSH (1997); Walker-Bone \& Palmer } \\
\text { (2002); Rosecrance et al. (2006); Davis } \\
\text { (2007); Osborne et al. (2010); Fathallah } \\
\text { (2010) }\end{array}$ \\
\hline $\begin{array}{l}\text { Elbow disorders such as } \\
\text { epicondylitis }\end{array}$ & $\begin{array}{l}\text { Forceful exertion } \\
\text { Repetition } \\
\text { Extreme postures }\end{array}$ & $\begin{array}{l}\text { NIOSH (1997); Davis (2007); Fathallah } \\
\text { (2010) }\end{array}$ \\
\hline $\begin{array}{l}\text { Hand/wrist tendonitis such as } \\
\text { carpal tunnel syndrome }\end{array}$ & $\begin{array}{l}\text { Repetition } \\
\text { Forceful exertion } \\
\text { Awkward posture }\end{array}$ & $\begin{array}{l}\text { NIOSH (1997); Walker-Bone \& Palmer } \\
\text { (2002); Davis (2007); Osborne et al. } \\
\text { (2010); Fathallah (2010) }\end{array}$ \\
\hline Low back disorders & $\begin{array}{l}\text { Heavy physical work } \\
\text { Lifting and forceful movements } \\
\text { Bending and twisting (awkward } \\
\text { postures) such as stooping } \\
\text { Whole-body vibration } \\
\text { Static work postures }\end{array}$ & $\begin{array}{l}\text { NIOSH (1997); Walker-Bone \& Palmer } \\
\text { (2002); Rosecrance et al. (2006); } \\
\text { Osborne et al. (2010); Davis (2007); } \\
\text { Fathallah (2010); Lee (2012) }\end{array}$ \\
\hline $\begin{array}{l}\text { Knee pain (including } \\
\text { osteoarthritis) }\end{array}$ & $\begin{array}{l}\text { Kneeling } \\
\text { Squatting } \\
\text { Prolonged standing }\end{array}$ & $\begin{array}{l}\text { Walker-Bone \& Palmer (2002); Davis } \\
\text { (2007); Osborne et al. (2010); Lee (2012) }\end{array}$ \\
\hline Ankle / foot pain & $\begin{array}{l}\text { Prolonged standing } \\
\text { Static posture }\end{array}$ & $\begin{array}{l}\text { Walker-Bone \& Palmer (2002); Davis } \\
\text { (2007) Osborne } \text { et al. (2010) }\end{array}$ \\
\hline
\end{tabular}

agricultural were an areas neglected despite being ones that warrant considerable attention ${ }^{19,25)}$. The common perception of health-care providers was generally to focus on signs of pesticide exposure with the assumption that musculoskeletal disorders occur in conjunction with agricultural manual labor activities ${ }^{26)}$.

However, MSDs in agriculture began to receive attention from researchers and eventually became widely recognized at the beginning of 21 st century. The key turning point was preceded by continuous effort of national and international discussion, meetings and studies that consistently revealed that MSDs to be the most common ergonomic injuries in laborintensive agricultural practices, which was contrary to what was assumed, which were preventable ${ }^{26-29)}$.

Referring to the injuries or disorders of the locomotors apparatus, the muscles, nerves, tendons, joints and cartilage, of the upper and lower limbs, neck and lower back, MSD or work-related MSD $^{30}$ ) have commonly been associated with agricultural practices corresponding to rigorous labor-intensive work tasks in terms of a multitude of ergonomic risk factors ${ }^{20,22,26,31)}$ (Table 1).

In a search of the literature, only local publications were found to contain studies related to occupational health at the oil palm plantation. Their cross-sectional studies revealed a high prevalence of MSD among harvesters and loaders of different sociodemographic 
backgrounds ${ }^{36,37)}$. Additionally, type of work, age and work duration and overtime work were also reported to be significantly associated with MSD in addition to ergonomics risk factors.

Previous reports have shown that harvesting tasks have been associated with the risk of developing musculoskeletal disorders. These disorders are usually the result of repeated exposure to stresses that develop slowly over time ${ }^{34)}$. Particularly, pain in the hand, arms, shoulders, neck, back and waist are the most commonly reported symptoms in association with production agriculture $22,31,38$ ).

Risks factors such as rapid, repetitive motions, sustained static loading, awkward posture, externally applied compressive forces and vibration or any combination of them have also been reported to be stressful to one or more body regions ${ }^{22,27,31)}$. For example, manual lifting associated with heavy load, working in stooping postures and repetitive hand work are the main risk factors of utmost concern in agriculture $^{20,21,27)}$. Stooping was stressed in biomechanical research relating high spinal compression forces during stooping to considerable epidemiological evidence linked to low back disorders ${ }^{39}$.

With regards to further risk factors, the National Research Council and Institute of Medicine (2001) has proposed a conceptual model illustrating the complex interrelationship of workplace, organizational and social factors as well as individual factors that may contribute to the development of MSD. In addition, the harvesters may also concurrently be affected by different cultural, organizational, psychosocial and individual risk factors.

Specifically, where foreign labor is involved, homesickness, health and socioeconomic well-being of the family as well as smoking habit and being overweight may increase the risk of developing MSD. These risk factors have been shown in various studies to be significantly associated with $\mathrm{MSD}^{30,31)}$.

Nonetheless, it is important to note that different job tasks and different stages of the OPP presents significantly different risks in terms of workplace environment ergonomics associated with affected body parts. Hence, it is crucial to report the type of work and stages of harvesting at the OPP or the height of the trees/age when presenting findings, particularly those related to the outcome of ergonomics research or interventions conducted.

\section{Conclusions}

Despite the few locally published studies, the presently available literature indicates a shortfall of healthrelated research in the OPP. This situation is further taken lightly, with workers themselves possibly not reporting any pain experienced for fear of losing their job or their wages being affected.

With the current focus and investment heavily skewed towards the upstream OPP, the sustainability of occupational safety and health in terms of the social aspect is questionable. Analyses of the work tasks of oil palm harvesters as discussed above indicate a considerable ergonomics risk factors for development of MSDs which should not be taken lightly.

In the long term, the risks posed may be both physical and economic, which may tilt the balance of sustainability. This is especially true as harvesters play a significant role in the labor-intensive tasks. Based on the currently available literature, there is need for further studies to be conducted in different geographical locations among workers with different sociodemographic backgrounds.

Better reporting systems and surveillance data are warranted in order to create widespread awareness and attention particularly among the stakeholders to justify the need for cost-effective intervention, which is sometimes referred to as agricultural extension.

The need of effective intervention has been expressed by many peers in the field of ergonomics research in order to improve the workplace environment by addressing comprehensively ergonomic aspects in order to tackle the costly MSDs.

Thus, the strategy and design of effective intervention related to agricultural ergonomics must take into consideration the work environment, task and commodity specifics, while implementation should be participatory, culturally and socially acceptable for the OPP.

Acknowledgment: This project was financially funded by the Research University Grant Scheme, Initiative 4 (Grant No.: 9305800), of the Universiti Putra Malaysia under the Ministry of Higher Education, Malaysia.

\section{References}

1) Seegräf M, May D, Breuer T, Schukat P. Palm oilsustainability is possible! Promotion and certification of smallholders helps sustainable palm oil production. Eschborn (Germany): Deutsche Gesellschaft für Technische Zusammenarbeit (German Agency for Technical Cooperation); 2010.

2) Nellemann C, MacDevette M, Manders T. 2009 The environmental food crisis-The environment's role in averting future food crises. A UNEP rapid response assessment. United Nations Environment Programme. Birkeland Trykkeri AS (Norway); GRID-Arendal: 2006.

3) Msangi S, Rosegrant M. World Agriculture in a Dynamically-Changing Environment: IFPRI's Longterm Outlook for Food and Agriculture under Additional Demand and Constraints. High Level 
Expert Forum on How to Feed the World in 2050. 2009; 12-3.

4) Atabani AE, Silitonga AS, Badruddin IA, Mahlia TMI, Masjuki HH, Mekhilef S. A comprehensive review on biodiesel as an alternative energy resource and its characteristics. Renewable and Sustainable Energy Reviews 2012; 16: 2070-93.

5) Thoenes P. Biofuels and commodity marketspalm oil focus, Paper based on presentation at AgraInforma Conference on The Impact of Biofuels on Commodity Markets. Brussels: Food and Agriculture Organization, Commodities and Trade Division; 2006.

6) Economics Transformation Programme. Chapter 9: Deepening Malaysia's Palm Oil Advantage. [Online]. 2010 [cited 2012 Oct 9]; Available from: URL: http://etp.pemandu.gov.my/upload/etp_handbook_cha pter_9_palm_oil.pdf

7) MVO. Fact Sheet - Palm Oil. [Online]. 2012 [cited 2012 Oct 9]; Available from: URL: http://www.mvo. nl/LinkClick.aspx?fileticket=jsFVMZwZzkc\%3D

8) Poku K. Small Scale Palm Oil Processing in Africa. Food \& Agriculture Org; 2002.

9) Basiron Y. Palm oil and its global supply and demand prospects. Oil Palm Industry Economic Journal 2002; 2 : 1-10.

10) Corley RHV. Palm oil for world food needs. Global Oils \& Fats Business Magazine. Malaysia: Malaysian Palm Oil Promotion Council; 2005; 2: 6-13.

11) United Nations Development Programme. Malaysia Generating Renewable Energy from Palm Oil Wastes. Kuala Lumpur (Malaysia): UNDP; 2007.

12) Basiron Y. Palm oil production through sustainable plantations. European Journal of Lipid Science and Technology 2007; 109: 289-95.

13) Teoh CH. Key sustainability issues in the palm oil sector. A discussion paper for multi-stakeholders consultations (Commissioned by the World Bank Group); 2010.

14) Rist L, Feintrenie L, Levang P. The livelihood impacts of oil palm: smallholders in Indonesia. Biodiversity and Conservation 2010; 19: 1009-24.

15) Hashim K, Yuen Y. Peaceful Co-existence. Global Oils and Fat Business Magazine 2007; 4: 6-12.

16) Henriksson J. European Delegacy to Malaysia, 2012. The Malaysian palm oil sector overview. [Online]. 2010 [cited 2012 Oct 9]; Available from: URL: http://www.ice.gov.it/paesi/asia/malaysia/upload/173/ Palm\%20Oil_overview_2012.pdf

17) Adnan H. Labor shortage to get worse with Indonesian oil palm boom. The Star Online 2012 May 29. Kuala Lumpur (Malaysia): Star Publications Bhd.

18) Abdullah R, Ismail A, Khomeini A, Rahman A. Labor requirements in the Malaysian palm oil industry in 2010. Oil Palm Industry Economic Journal 2011; 11: 1-12.

19) Rainbird G, O'Neill D. Occupational disorders affecting agricultural workers in tropical developing countries: results of a literature review. Appl Ergon 1995; 26: 187-93.

20) Fathallah FA. Musculoskeletal disorders in laborintensive agriculture. Appl Ergon 2010; 41: 738-43.

21) General Association of Engineers in Romania (AGIR). Musculoskeletal Disorders in Agriculture. [Online]. 2012 [cited 2012 Oct 15]; Available from: URL: http://www.agir.ro/buletine/1276.pdf

22) Kirkhorn SR, Earle-Richardson G, Banks RJ. Ergonomic risks and musculoskeletal disorders in production agriculture: recommendations for effective research to practice. J Agromedicine 2010; 15: 281-99.

23) Kotowski SE, Davis KG, Waters TR. Investigation of select ergonomic interventions for farm youth. Part 2: wheelbarrows. J Agromedicine 2009; 14: 44-57.

24) Mutert E, Fairhurst TH. Twenty-two tips for practical oil palm planters. Better Crops International 1999; 13: 7-8.

25) Solecki L. Current state of ergonomics in agriculture--future needs. VIII International Symposium on Ergonomics, Work Safety and Occupational Hygiene. 22-24 October 2001, Lublin. Ann Agric and Environ Med 2001; 8: 297.

26) Chapman L, Meyers J. Ergonomics and musculoskeletal injuries in agriculture: recognizing and preventing the industry's most widespread health and safety problem. Agricultural Safety and Health Conference Proceedings. 2001 March 2-3; Baltimore (MD): 2001.

27) Meyers JM, Miles JA, Tejeda DG, et al. Priority risk factors for back injury in agricultural field work: vineyard ergonomics. J Agromedicine 2002; 8: 39-54.

28) International Labour Organization. Report VI (1) Sixth item on the Agenda: Safety and Health in Agriculture. Geneva: ILO; 2005.

29) McCurdy SA, Samuels SJ, Carroll DJ, Beaumont JJ, Morrin LA. Agricultural injury in California migrant Hispanic farm workers. Am J Ind Med 2003; 44: 225-35.

30) Bernard BP, Putz-Anderson V, Burt SE. A critical review of epidemiologic evidence for work-related musculoskeletal disorders of the neck, upper extremity, and low back. Cincinnati $(\mathrm{OH})$ : Centers for Disease Control and Prevention National Institute for Occupational Safety and Health Publication; 1997. p. 97-141.

31) Sesto M. Chronic Musculoskeletal Disorders in Agriculture for Partners in Agricultural Health. University of Wisconsin-Madison. [Online]. 2000 [cited 2012 Oct 15]; Available from: URL: http:// www.worh.org/files/AgHealth/musc.pdf

32) Walker-Bone K, Palmer KT. Musculoskeletal disorders in farmers and farm workers. Occup Med 2002; 52: 441-50.

33) Rosecrance J, Rodgers G, Merlino L. Low back pain and musculoskeletal symptoms among Kansas farmers. Am J Ind Med 2006; 49: 547-56. 
34) Davis KG, Kotowski SE. Understanding the ergonomic risk for musculoskeletal disorders in the United States agricultural sector. Am J Ind Med 2007; 50: 501-11.

35) Lee CG. Work-related musculoskeletal disorders in Korean farmers. Journal of Korean Medical Association 2012; 55: 1054-62.

36) Mohd Nizam J, Rampal KG. Study of back pain and factors associated with it among oil palm plantation workers in selangor. Journal of Occupational Safety and Health 2005; 2: 36-41.

37) Hendra, Rahardjo S. Risiko Ergonomi dan Keluhan Musculoskeletal Disorders (MSDs) Pada Pekerja Panen Kelapa Sawit.; Semarang (Indonesia):
2009; Prosiding Seminar Nasional Ergonomi IX p. D11-1-8.

38) Osborne A, Blake C, Fullen BM, et al. Prevalence of musculoskeletal disorders among farmers: a systematic review. Am J Ind Med 2012; 55: 143-58.

39) Fathallah FA, Meyers JM, Janowitz I. Stooped and squatting postures in the workplace. Proceedings of the symposium for stooped and squatting posture in the workplace. 2004 July 29-30; California, USA.

40) National Research Council, The Institute of Medicine. Musculoskeletal disorders and the workplace: Low back and upper extremities. Washington, DC: National Academy Press, 2001. 